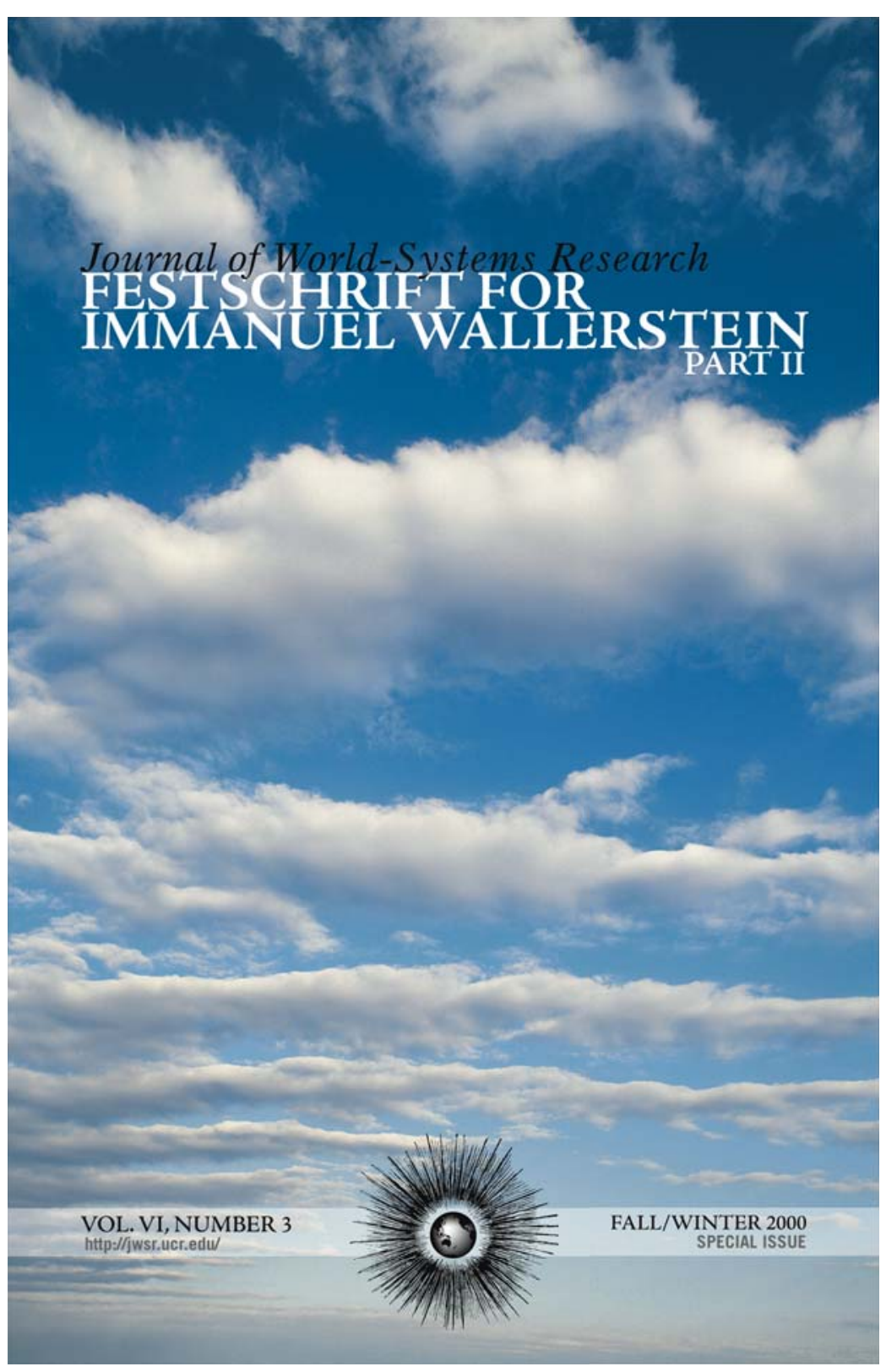

The Structures of Knowledge and the Future of the Social Sciences: Two Postulates, Two Propositions and a Closing Remark

Richard E. Lee

First Postulate: The production and reproduction of the structures of knowledge has been a process constitutive of and constituted by the Modern World-System.

Crom the beginning of the long sixteenth century, the practices of - knowledge production took the form of a complex of processes which produced over time an intellectual and institutional hierarchy within which authoritative knowledge was progressively defined as the "other" of societal/ moral values. These processes of knowledge formation, in articulation with those sets of processes associated with the "economic" and "political" spheres, account for the dominant relational setting "disciplining" human cognition, and thus the "cultural" parameters of action. This long-term pattern of the modern world-system we shall call the structures of knowledge. ${ }^{1}$

A determining micro-fluctuation indicating the direction of the transformation that the far-from-equilibrium modes of knowing would take

Richard E. Lee

Fernand Braudel Center

Binghamton University

State University of New York

Binghamton, NY 13902-6000

http://fbc.binghamton.edu/

rlee@binghamton.edu

1. Terence K. Hopkins discussed the "two sets of processes," processes of the "worldscale division and integration of labor" and "processes of state-formation and deformatio... that constitute the system's formation and provide an account, at the most general level, for the patterns and features of its development" (1982: 12). Hopkins, Wallerstein et al., however, also claimed that there was "a third fundamental aspect to the modern worldsystem...the broadly 'cultural' aspect... even though little is systematically known about it as an integral aspect of world-historical development... [and] much preliminary conceptual work needs to be done" (1982: 43).

JOURNAL OF WORLD-SYSTEMS RESEARCH, VI, 3, FALL/WINTER 2000, 786-796 Special Issue: Festchrift for Immanuel Wallerstein - Part II bttp://jwsr.ucr.edu

ISSN $1076-156 \mathrm{x}$

(C) 2000 Richard E. Lee 
during the transition from feudalism to capitalism in Europe was the emergence of the "modern fact" as the primary epistemological unit of valid knowledge and cultural authority. ${ }^{2}$ The creation of the modern fact enabled the metamorphosis of the merchant into the capitalist by establishing the legitimacy of profit rooted in the virtues of "balance" inherent in the system of double-entry bookkeeping. With profit distinguished from usury, the accumulation of accumulation could take off. At the same time, however, there were collateral effects that redefined the structures of knowledge.

The modern fact could be affiliated with both specifics (of commerce) and their generalization (within a system which ordained the individual creditworthines of merchants and their credibility as a group). The possibility of such a double identity defined the contradiction between the particular and the universal that drove the processes of rationalization (which, depending on circumstances, might be labeled "scientization" or "secularization") to produce and reproduce the structures of knowledge over time. This contradiction has constantly reappeared embedded in an array of distinctive intellectual antinomies, such as subjective-objective, anarchy/chaos-order, value-truth, agency-structure, which, although formally homologous, have taken on the tonalities of the communities of discourse in which they have been deployed.

The pursuit of objectivity-the view from nowhere; the erasure of agency and history, in short, of subjectivity in whatever form (see Megill 1994) - arose as the confederate of the process of rationalization and embodies the progressive privileging of formal rationality, disinterested calculation as a generalized means of instrumental action, over substantive rationality, the normatively-oriented pursuit of specifically situated ends.

2. Here I draw on Mary Poovey's account of the emergence of the modern fact and its ambiguity (see Poovey 1998: ch. 1 and ch. 2, especially). The history she writes of "how description came to seem separate from interpretation or theoretical analysis; the story of how one kind of representation-numbers-came to seem immune from theory or interpretation" (1998: xii) bears directly on the structures of knowledge approach. The conceptual tools developed at this level of abstraction can then be deployed as I have done here (and for which I bear responsibility) and suggest paths to be explored in the analysis of the formation and disintegration of cultural communities (and the individual identities they shape) and the relationship of these processes with the other organizing tendencies of historical capitalism (e.g., Lee 1998a).
With the common purpose of mastering nature, two avenues in the search for truth independent of received values (signaling the decline of rhetoric on which the authority of generalizations drawn from deracinated specifics had originally been erected) were charted in empiricist appeals to the senses and an inductive method and rationalist espousals of reason and a deductive method. During the eighteenth century, the medium-term, Newtonian fusion of these two antithetical modes produced a tense synthesis of experiments and empirical approaches with hypotheses and mathematical demonstrations. Classical science henceforth would be concerned with the discovery of universal laws governing a regular and constant nature that would lead to the prediction of change, both future and past. With the displacement of the divine viewpoint to man, the humanities, not concerned with the ordered certitude of regularities in the world of nature but with the chaotic finitude of the unique and unpredictable in the human world of conflicting values, could appeal to individual creativity for a "rational" understanding of emergence and change. Along these two lines, the long-term intellectual and institutional structural opposition of the sciences and the humanities, what has come to be called the "Two Cultures," reached a clear delineation over the course of the nineteenth century.

Second Postulate: The social sciences emerged in the nineteenth century as a medium-term solution to the tensions internal to the structures of knowledge.

To envision a static world in the aftermath of the French Revolution was inconceivable; however, modes of interpreting social change in the human world, as marked off from the natural world, made uncomfortable appeals to values. The possibilities, expressed in the form of a mutually exclusive opposition, were either order achieved through the authority of tradition or chaos arising from unfettered democracy, and neither offered a consensual solution to the political confrontations between conservatism and radicalism that threatened capital accumulation. Eventually, from the late nineteenth century, the objective, value-neutral, problem-solving spirit of science was advanced to resolve the standoff in the English-speaking world and the connection between meaning or values and systematic knowledge was argued rigorously in the Methodenstreit, especially in the Germanies. The result was the institutionalization of a set of disciplines, the social sciences, which would function to guarantee ordered change in the name of "progress" 
through scientific control, exercised by "experts" and based on "hard facts"; in practice, this amounted to liberal incrementalism maximizing accumulation and minimizing class struggle.

The evolving hierarchical structure of the sciences, the social sciences and the humanities privileged, as authoritative, the universalism of the sciences, the empirical and positivistic sphere of "truth," over the particularism of the humanities, the impressionistic and anarchic realm of "values". The social sciences came to be situated in-between, resolving in the medium term the crisis of social knowledge formation of the nineteenth century. Although economics, political science and sociology leaned more toward the sciences while history, Oriental studies and anthropology tended to be more humanistic, even within the disciplines there was no consensus on the composition of their data (quantitative, qualitative), or the appropriateness of their methods (statistical, narrative), or the nature of their "scientific" universality (discovery of laws, elaboration of descriptions) on which they based the legitimacy of their claims.

At crosscurrents with a holistic experience of social relations, the social sciences divided the study of the human world into isolated domains separated intellectually in disciplines and institutionally in university departments. Oriental studies and anthropology were concerned with the great civilizations and the "tribes" of the non-modern world respectively; history handled the past of the modern world; the present of the modern world was further divided among economics, political science and sociology which treated the market, the state, and civil society as isolated fields. ${ }^{3}$

However, from the moment of the greatest intellectual and institutional success of this structure in the period immediately after 1945, the scholarly

\footnotetext{
3. Immanuel Wallerstein has set out this organizational structure in a number of the articles listed below. In 1971, he declared that "[ $t$ ] here is no such thing as sociology if by sociology we mean a discipline' that is separate and distinct from anthropology, political science, economics, and history (not to speak of demography and so on). They are all one single discipline which I suppose we may call social science" (1971b: 328). He has continued to write extensively on the past and future of the social sciences (see especially Wallerstein et al. 1996; Wallerstein 1991, 1998a and 1999), the questions of objectivity and truth (e.g., Wallerstein 1971a and 1979), and the two cultures split (e.g., Wallerstein 1998b).
}

legitimacy of the premises underlying the partitions separating the disciplines and the practical usefulness of the distinctions became less and less self-evident, and after 1968 were overtly contested.

First Proposition: The structures of knowledge have entered into systemic crisis.

As a practical matter, in the United States where disciplinary/ departmental divisions were most sharply defined, the expansion of the university system after 1945 created a demand to produce more Ph.D.'s and therefore a demand for dissertation research projects. In order to fulfill expectations of originality, the real work scholars did increasingly disregarded disciplinary firewalls within the social sciences. Evidence of this trend is to be found in the proliferation and institutionalization of sub-disciplines which have added up to a significant blurring of the boundaries over the past fifty years.

Nonetheless, it was only in the 1960's that direct challenges to the structures of knowledge, both to the differentiation and compartmentalization of the social science disciplines and to the hierarchy of the Two Cultures, began in earnest. Work in diverse fields of the social sciences and the humanities, coming together under the rubric "cultural studies," led to conclusions and interpretations tending to delegitimate the universalist premises on which the relational structure of the natural sciences, the social sciences, and the humanities had been built. At the level of theory, literary structuralism offered the possibility of developing a non-reductionist, nonpositivist human science concerned with that prototypical social activity, the making of meaning. At the level of practice, developments growing out of studies focusing on marginalized groups, such as women and ethnic and racial "minorities," challenged the fact-values divide by illustrating how essentialist, received categories of difference have functioned to inscribe whole groups into subordinate stations on status hierarchies legitimating differential access to social goods. New disciplinary/departmental groupings have also been institutionalized as these groups, formerly excluded from full participation in the university, were incorporated into the scholarly community.

At the opposite end of the disciplinary continuum, "complexity studies" were a direct outgrowth of developments in mathematics and the natural sciences and as such take a position of particular importance completing, as 
they do, the disciplinary range of challenges to the long-term structures of knowledge. Although over the course of the twentieth century relativity and quantum mechanics undermined the presumptions of classical science at the level of the very large and the very small, it is (again) only since the 1960's that Newtonian dynamics has been challenged in the macro, humanly perceivable, non-relativistic, non-quantum domain. The present rethinking marks a transition away from the world view emphasizing the equilibrium and stability inherent in time-reversible natural laws to a reconceptualization of the (natural) world (to more closely resemble the social world) as one of instability, complexity and self-organization, a world whose deterministic yet unpredictable development exhibits an arrow-of-time (see Prigogine 1997).

Thus, on the one hand, it may be said that the frontier between the humanities and the social sciences is collapsing. The uniquely modern concepts of independent object and autonomous creator have come under serious attack from the humanities and that social construct, the self-interested but responsible individual, the liberal—white, male—subject, has lost "his" foundations.

On the other hand, the concurrent emphasis in complexity studies on contingency, context-dependency, and multiple, overlapping temporal and spatial frameworks is moving the sciences in the direction of the historical social sciences and their concern for spatial-temporal wholes comprised of both the relational structures of human interaction and the phenomenological time of their development. The identification and study of the feedback mechanisms of complex systems, including historical social systems, denies the possibility of an "objectivity" defined as a form of externalism. It is, then, not just that new models of complex systems are being made available to social scientists (unfortunately all too often applied like cookie-cutter templates), but rather that the ontological, as well as epistemological, underpinnings of the claims to legitimacy of knowledge constructed on the "scientific" and "humanistic" models is undergoing a transformation. ${ }^{4}$

4. On challenges to the structure of the disciplines after 1945, see Lee (1996).
Second Proposition: The uncertainty of the future opens up the character of knowledge production and the definition and role of the knowledge producer.

The modern world-system is a historical system. It is systemic in that its structures have remained recognizable over its lifetime; it is historical in that those structures came into being, have changed constantly, and will eventually cease to exist. In the long term, the evolution of the structures of knowledge (trends) has been returned to relative equilibrium as normal fluctuations were damped (cycles), but seems now to have reached a "farfrom-equilibrium" point of no return. Indeed, it was the argument advanced in The Age of Transition: Trajectory of the World-System 1945-2025 (Hopkins, Wallerstein et al. 1996) that the entire complex of processes of the modern world-system was approaching a set of asymptotic limits signaling a transformation of the system as a whole. ${ }^{5}$

Systemic transformation, however, is not immediate and abrupt but, in the language of the new sciences of complexity, takes the form of a bifurcation arising out of a period of transition characterized by chaotic fluctuations. By definition, such a period (the next fifty years perhaps) is one of great disorder. But as a consequence, that medium-term future also presents great possibilities, for unstable systems pose fewer constraints and very small fluctuations, now capable of massive amplification, could determine the direction any transformation might take. Free will can be expected to find greater latitude while the potential effects of individual agency will multiply.

In Utopistics: Or, Historical Choices of the Twenty-first Century, Immanuel Wallerstein suggests that during this crucial period of struggle "there are two large questions before us: what kind of world do we in fact want; and by what means, or paths, are we most likely to get there." The first he addresses in "terms of utopistics, that is, the serious assessment of historical alternatives, the exercise of our judgment regarding the substantive rationality of possible alternative historical systems" and presents the second "in terms of the end of certainty, the possibility but the non-inevitability of

5. On this "upper bound of the trajectory of historical capitalism," see my "After History? The Last Frontier of Historical Capitalism" (Lee 2001). 
progress" (1998c: 65) ${ }^{6}$ The future intellectual and institutional organization of knowledge production remains "uncertain" and to be constructed. In this context one thing is certain, "social science in the twenty-first century... will be an intellectually exciting arena, a socially important one, and undoubtedly a very contentious one" (Wallerstein 1999). However, as the recognition that all knowledge has a social aspect gains ground and the possibilities of "containing" the study of human reality within existing disciplinary arrangements becomes increasingly dubious, it remains unclear "what is to be done".

At this point, I would like to offer a thought on immediate action for those of "us" whose primary activities center on the university community. I have stated previously (Lee 1998b) that the combination of freedom and reason C. Wright Mills conceived as persuasion, today all too often taking the form of a pluralism blind to relations of power and privilege, no longer seems to adequately express the ethical imperative on the part of the individual social scientist to actively participate in the struggle Wallerstein envisions. I want to suggest that one way that role can be played out is in confrontation, and the confrontation I am talking about is among alternative models of social reality presented by flesh-and-blood advocates and the logical consequences those alternative conceptual schemes generate when pressed to their limits.

Direct advocacy favors the disclosure of the articulation of symbolic codes and material practices and thus the exposure of the historical construction of relations of authority and legitimacy. Direct advocacy fosters the recovery of the link between values and difference and thereby undermines the separation of personal morality from professional neutrality. It is not just representation that is at stake. From this perspective, beyond the institutions and mechanisms through which knowledge is produced (but mostly reproduced) and the premises grounding that production, it should

6. Wallerstein has speculated on the future of the social sciences in a soon to appear UNESCO report (Wallerstein 1999) and some suggestions for structural change within academia are to be found at the end of the Gulbenkian Commission Report on the Restructuring of the Social Sciences (1996). not come as a surprise if the agenda of transition were to include "unthinking" the definition and role of the knowledge producer.

Just as the subject/object relation has become problematic, we need to reconsider the professor/student relation in order to script a new, collaborative subject, in recognition of the ultimate social construction of knowledge and in tune with the lives of real men and women caught up in the making of a new world. In response to the "culture wars" and the "crisis of the humanities," Gerald Graff (1992; Cain 1994) has proposed "teaching the conflicts". If that were to mean simply presenting opposing points of view in a marketplace of ideas limited to a single classroom, it would not get us very far. Exploding the individual, self-contained classroom as the standard unit of "instruction" by staging the debates at the center of the curriculum, on the other hand, would create intellectual communities with the tendency to frustrate a di Lampedusan solution of changing everything in order that nothing change.

Experiments with such proposals are actually underway on a few campuses. This type of initiative has the advantage of being fundable and can be designed to satisfy objectives dear to the hearts of administrators while at the same time stimulating the production of imaginative responses, in the form of explorations of serious historical alternatives to the structural limits of endless accumulation. It should be of no small consideration that innovations leading to a more substantively rational historical system are more likely to be institutionalized if they possess the advantage of initially grounding their validity in existing structures of authority.

\section{Closing Remark}

Immanuel Wallerstein has written that world-systems analysis, as an unfinished critique of nineteenth-century social science "has not been able to find a way to surmount the most enduring (and misleading) legacy of nineteenth-century social science-the division of social analysis into three arenas, three logics, three levels - the economic, the political, and the sociocultural. This trinity stands in the middle of the road, in granite, blocking our intellectual advance" (1991: 4).

In conclusion, I want to suggest that the structures of knowledge approach with its emphasis on processes and TimeSpace rather than categories and development can bring us one step closer to the goal of con- 
structing the historical social sciences and achieving a more useful vision of long-term, large-scale social change.

\section{REFERENCES}

Cain, William E., ed. (1994). Teaching the Conflicts: Gerald Graff, Curricular Reform, and the Culture Wars. New York: Garland.

Graff, Gerald (1992). Beyond the Culture Wars: How Teaching the Conflicts Can Revitalize American Education. New York: Norton.

Hopkins, Terence K. (1982).“The Study of the Capitalist World-Economy: Some Introductory Considerations," in Terence K. Hopkins, Immanuel Wallerstein and Associates. World-Systems Analysis: Theory and Methodology. Beverly Hills: Sage, 9-38.

Hopkins, Terence K., Immanuel Wallerstein et al. (1982). "Patterns of Development of the Modern World-System," in Terence K. Hopkins, Immanuel Wallerstein and Associates. World-Systems Analysis: Theory and Methodology. Beverly Hills: Sage, 41-82.

Hopkins, Terence K., Immanuel Wallerstein et al. (1996). The Age of Transition: Trajectory of the World-System 1945-2025. London: Zed Books.

Lee, Richard (1996). “Structures of Knowledge,” in Terence K. Hopkins, Immanuel Wallerstein et al. The Age of Transition: Trajectory of the World-System 1945-2025. London: Zed Books, 178-206.

Lee, Richard (1998a)."The Politics of Accumulation in Victorian England: Race, Gender and the World Class Struggle," Paper delivered at the Conference "The Image of Class in Literature, the Media, and Society," Colorado Springs, CO (University of Southern Colorado), 12-14 March 1998.

Lee, Richard (1998b). Complexity Studies and the Human Sciences: Pressures, Initiatives and Consequences of Overcoming the Two Cultures. México, D.F.: UNAM/CIIECH.

Lee, Richard (2001). "After History? The Last Frontier of Historical Capitalism," Protosoziologie, 15, January, 87-104.

Lee, Richard (forthcoming). "The 'Cultural Aspect' of the Modern World-System: Social Movements and the Structures of Knowledge," in Inequality and Social Movements. Edited by Nancy Forsythe and Roberto Patricio Korzeniewicz. Westport: Greenwood.

Megill, Allan, ed (1994). Rethinking Objectivity. Durham: Duke University Press.

Poovey, Mary (1998). A History of the Modern Fact: Problems of Knowledge in the Sciences of Wealth and Society. Chicago: University of Chicago Press.

7. The explicit, detailed justification for the claim that the structures of knowledge approach effectively captures the "cultural" dimension of social change may be found in my "The 'Cultural Aspect' of the Modern World-System: Social Movements and the Structures of Knowledge" (Lee, forthcoming).
Prigogine, Ilya (1997). The End of Certainty: Time, Chaos, and the New Laws of Nature. New York: Free Press.

Wallerstein, Immanuel (1971a)."Lorganization des sciences humaines et l'objectivité," Cabiers Internationaux de Sociologie, nouvelle série, L, 41-48.

Wallerstein, Immanuel (1971b). "There is no Such Thing as Sociology," The American Sociologist, 6, 4, November, 328.

Wallerstein, Immanuel (1979)."Some Reflections on History, the Social Sciences, and Politics," The Capitalist World-Economy. Cambridge/Paris: Cambridge University Press/Editions de la Maison des Sciences de l'Homme, vii-xii.

Wallerstein, Immanuel (1991). Unthinking Social Science: The Limits of Nineteenth-Century Paradigms. Cambridge: Polity Press.

Wallerstein, Immanuel (1998a)."The Heritage of Sociology, the Promise of Social Science," Current Sociology, XLVI, 2 April.

Wallerstein, Immanuel (1998b)."Time and Duration: The Unexcluded Middle, or Reflections on Braudel and Prigogine," Thesis Eleven, 54, August, 79-87.

Wallerstein, Immanuel (1998c). Utopistics: Or Historical Choices of the Twenty-first Century. New York: The New Press.

Wallerstein, Immanuel (1999). "Social Sciences in the Twenty-first Century," in A. Kazancigil and D. Makinson, eds., World Social Sciences Report. Paris: UNESCO/ Elsevier, 42-49.

Wallerstein, Immanuel et al. (1996). Open the Social Sciences: Report of the Gulbenkian Commission on the Restructuring of the Social Sciences. Stanford, CA: Stanford University Press. 